\title{
Effect of soot on tribological properties of steel and ceramic contacts
}

\author{
Yadvendra Kaushik and P. Ramkumar* \\ Machine Design Section, \\ Department of Mechanical Engineering, \\ Indian Institute of Technology Madras (IITM), \\ Chennai 600036, India \\ Email: kaushikyadvendra@gmail.com \\ Email: ramkumar@iitm.ac.in \\ *Corresponding author
}

\begin{abstract}
The present study aims to understand the effect of soot on tribological properties using different tribo-couples of bearing steel, silicon nitride and zirconia. The present test programme is performed using a pin-ondisc tribometer with LVDT, temperature and friction transducers. All tests are carried out at a sliding speed of $5 \mathrm{~m} / \mathrm{s}$ and contact stress of $2.05 \mathrm{GPa}$ to simulate a typical valve-train operation condition in diesel engine. Commercially available heavy-duty diesel engine oil is used as lubricating oil. Friction and wear results are studied at different levels of soot concentration. Silicon nitride shows the lowest friction and wear against the bearing steel amongst the all tribo-couples. Post-test analysis is carried out using optical microscope and SEM with EDX of the worn surfaces of the pin materials to identify the wear mechanisms. Abrasive wear mechanism was found to be the primary wear mechanism for all tribo-couples. A delamination wear mechanism is proposed for zirconia in presence of soot contamination.
\end{abstract}

Keywords: ceramic; friction; soot; wear; zirconia.

Reference to this paper should be made as follows: Kaushik, Y. and Ramkumar, P. (2019) 'Effect of soot on tribological properties of steel and ceramic contacts', Int. J. Materials and Structural Integrity, Vol. 13, Nos. $1 / 2 / 3$, pp.172-185.

Biographical notes: Yadvendra Kaushik is an Engineering Analyst at Oceaneering International. He is a former Research Scholar of Indian Institute of Technology Madras and received a MS degree in Mechanical Engineering (2018). He is a graduate of the University of Aeronautical Society of India from which he received a Bachelor's degree in Aeronautical Engineering (2012).

P. Ramkumar is working as an Assistant Professor in the Department of Mechanical Engineering, IIT Madras. He obtained his BE in Mechanical Engineering from College of Engineering Guindy, Anna University and MTech (Industrial Tribology) from IIT Madras. He pursued PhD (2003-2007) from University of Southampton, UK and post-doctoral fellowship in University of Leicester (2009-2010), UK. He has 11 years research experience in the field of tribology and engine tribology. His primary research interests are in the field of tribology, WEC bearing failures in WTG, DLC coatings with surface texturing, wear modelling and developing new materials for brake application. 
This paper is a revised and expanded version of a paper entitled 'Effect of soot on tribological properties of steel and ceramic contacts' presented at Indian Conference on Applied Mechanics (INCAM)', MNNIT Allahabad, 5-7 July 2017.

\section{Introduction}

Automobile industries are giving more attention to achieve better efficiency of vehicles at the same time maintaining stringent standard rules. Valve train components in heavy-duty diesel engine vehicles operate under high loading conditions as well as high temperature ranges. Several contaminants enter during the running-in conditions of diesel engine and make severe corrosive environments. Advanced ceramics and emerging intermetallic materials are highly resistant to corrosion, oxidation and wear, because of their better mechanical properties compared to conventional ferrous materials. Several studies have been performed on ceramics such as silicon nitride, silicon carbide, silicon carbide nitride, zirconia, and alumina. However, the behaviour of these materials in the presence of diesel engine contaminants is still not fully understood. Liao et al. (2016) studied the molecular structure of amorphous silicon carbon nitride using atomistic simulations. The silicon carbon bond was found stable after addition of additional carbon element. Contamination of lubricating oil by diesel soot is one of the major causes of increased engine wear. Experiments have been performed to investigate the effect of soot on tribological properties. Soejimaa et al. (2002) showed that wear increased as soot was introduced into the lubricant. Effect of soot was reduced with ZnDTP anti-wear additive. Friction changed more intensively in presence of soot. Penchaliah et al. (2011) performed a study on different contaminants such as sulphuric acid, oxides, moisture and diesel soot using steel-on-steel sliding contact. Wear was found largely affected by diesel soot and sulphuric acid than oxidation and moisture contaminants. The effect of diesel engine conditions on the size and morphology of soot particles has been investigated by Lapuerta and Ballesteros (2009). A significant increase in the apparent density of soot particles with increasing engine speed has been found. New silicon nitride ceramics with improved tribological properties were made to replace existing bearing steel in spark ignition, diesel and gas turbine automotive engines (Wyczalek, 1990). Silicon nitride has been investigated extensively for use in automotives but need to be explored in presence of contaminants, particularly soot. Further, zirconia has shown its potential for severe situations as it is harder than metals, tougher than other ceramics, chemically inert and retains these properties to at least $800^{\circ} \mathrm{C}$ (Hannink et al., 1984). For the increasing demand of zirconia in automotive industries, it is required to examine the properties of zirconia in presence of soot contaminant.

This work attempts to explore the performance of silicon nitride and zirconia in diesel engine for valve-train conditions in presence of soot contaminant. It is expected that silicon nitride and zirconia will help in reducing the weight of valve-train components and also increase the life of engine components by reducing the effect of soot on components. The main objective of the present work is to investigate the performance of ceramics (silicon nitride and zirconia) in presence of soot contaminant and to compare the tribological results with those for bearing steel. 


\section{Experimental setup and testing conditions}

A pin-on-disc (PoD) tribometer was employed to carry out the experiments as shown in Figure 1. A LVDT was attached to the tribometer to measure the linear wear of pin and disc in micrometres. A strain gauge was used to measure the friction at the contact of pin and disc during the experiment. An ultrasonic bath was employed to prepare the homogeneous mixture of lubricant oil and soot. A peristaltic pump was used to ensure continuous flow of the mixture at a constant flow rate in between the contact of pin and disc. The Cannon-Fenske routine viscometer was used to measure the viscosity of the lubricant at different concentrations of soot.

Figure 1 Pin on disc test rig (see online version for colours)

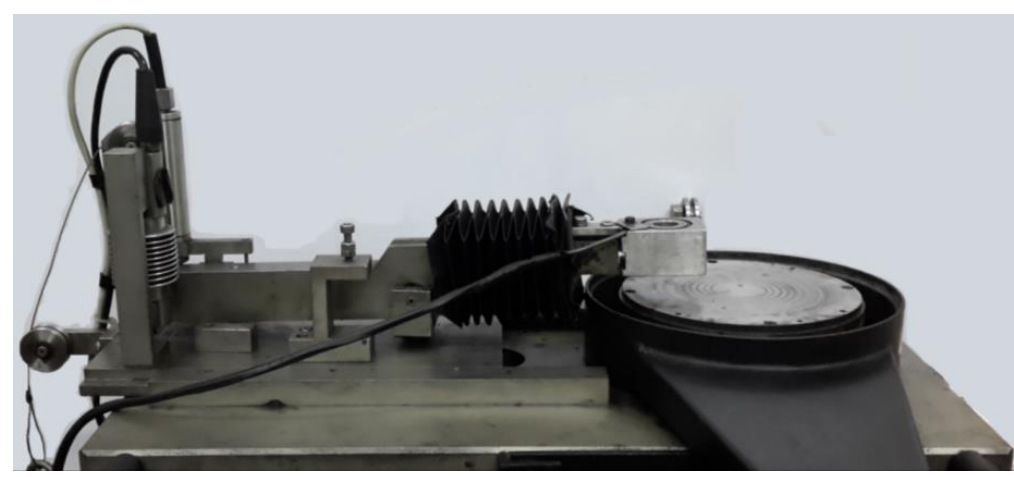

Table 1 Mechanical properties and dimensions of test specimens

\begin{tabular}{lccccc}
\hline \multirow{2}{*}{ Properties } & \multicolumn{3}{c}{ Pin (ball) } & & Disc \\
\cline { 2 - 4 } \cline { 5 - 6 } & Steel & $\mathrm{Si}_{3} \mathrm{~N}_{4}$ & $\mathrm{ZrO}_{2}$ & & Steel \\
\hline Young's modulus $(\mathrm{GPa})$ & 210 & 310 & 204 & & 210 \\
Density $\left(\mathrm{kg} / \mathrm{m}^{3}\right)$ & 7,800 & 3,250 & 6,010 & & 7,800 \\
Poisson's ratio & 0.3 & 0.27 & 0.31 & & 0.3 \\
Hardness Hv $\left(\mathrm{kg} / \mathrm{mm}^{2}\right)$ & 610 & 1650 & 1290 & & 420 \\
Surface roughness, $\mathrm{Ra}(\mu \mathrm{m})$ & 0.05 & 0.02 & & 0.02 & \\
Dimensions $(\mathrm{mm})$ & 10 dia. & 10 dia. & 10 dia. & & 165 dia. $\times 8$ thick \\
\hline
\end{tabular}

Table 2 Tribo-couples with different levels of soot in test matrix

\begin{tabular}{lllll}
\hline \multirow{2}{*}{ Tribo-couple } & \multicolumn{5}{c}{ Soot (\%wt./wt.) } \\
\cline { 2 - 5 } & 0 & 2 & 4 & 6 \\
\hline Steel-on-steel & $\checkmark$ & $\checkmark$ & $\checkmark$ & $\checkmark$ \\
$\mathrm{Si}_{3} \mathrm{~N}_{4}$-on-steel & $\checkmark$ & $\checkmark$ & $\checkmark$ \\
$\mathrm{ZrO}_{2}$-on-steel & $\checkmark$ & $\checkmark$ & $\checkmark$ & $\checkmark$ \\
\hline
\end{tabular}


Tests were carried out using bearing steel En31 (AISI 52100), silicon nitride and zirconia against En31 bearing steel. Among ferrous materials, En31 is the most suitable for tribological applications (Bhattarcharya et al., 2008). Table 1 shows the mechanical properties and dimensions of steel disc and steel pin (https://cni.in/shriram/), silicon nitride pin (http://www.vwimpex.com/) and zirconia pin (http://www.xzballbearing. $\mathrm{com} /$ ). Heat treatment for the En31 (AISI 52100) pin material was heat at 1,113 K $\left(840^{\circ} \mathrm{C}\right)$ for $20 \mathrm{~min}$ followed by quenching in oil at room temperature and then tempering at $433 \mathrm{~K}\left(160{ }^{\circ} \mathrm{C}\right)$ for 2 hours, hardness achieved as 610 . While, the En31 disc hardness is $420 \mathrm{Hv}$ but not heat treated. All tests were performed at a sliding speed of $5 \mathrm{~m} / \mathrm{s}$ and contact load of $50 \mathrm{~N}(1.5-2.05 \mathrm{GPa}$ initial Hertzian contact pressure) to simulate the valve train entrainment velocities and contact pressures of light duty diesel engines (Smiechowski and Lvovich, 2005). Table 2 shows the test matrix of different tribo-couple and soot concentrations (wt./wt.). Experiments were conducted at different levels of soot concentrations; $0 \%, 2 \%, 4 \%$ and $6 \%$, at least three times to ensure repeatability. Total 36 tests were performed at ambient conditions $\left(30-35^{\circ} \mathrm{C}\right)$ to analyse the tribological behaviour. Commercially available SAE $20 \mathrm{~W}-40$ diesel engine oil was used as a lubricant. The testing procedure used in all experiments involved first running of tribometer without loading for five minutes followed by lubrication for three minutes. An initial load of $10 \mathrm{~N}$ was applied over a period of five minutes and then load was ramped twice with an increment of $20 \mathrm{~N}$ at five minutes interval. Further experiment was continued for 60 minutes duration as steady state.

\subsection{SWR calculation}

The volume loss of worn pin can be measured using equation (1) (Gee, 1993)

$$
V L_{\text {pin }}=(\pi / 3) h^{2}(3 R-h)
$$

where $V L_{p i n}$ is the volume loss of worn pin (where $R, h \mathrm{in} \mathrm{mm}$ ), $R$ is the radius of pin and $h$ is the height of the worn pin and can be calculated using equation (2)

$$
h=R-\left(R^{2}-0.25 d^{2}\right)^{0.5}
$$

where $d$ is the wear scar diameter of pin.

The specific wear rate (SWR) can be calculated using equation (3)

$$
\mathrm{SWR}=\mathrm{VL} /(\mathrm{F} \times \mathrm{SD})
$$

where $\mathrm{F}$ is the force in Newton and $\mathrm{SD}$ is the sliding distance in metre.

\section{Results and discussion}

Results are summarised in Table 3 for steel-on-steel, $\mathrm{Si}_{3} \mathrm{~N}_{4}$-on-steel and $\mathrm{ZrO}_{2}$-on-steel respectively. Friction and wear results are specified at different concentration of soot contaminant. 
Table 3 Summary of results for steel-on-steel, $\mathrm{Si}_{3} \mathrm{~N}_{4}$-on-steel and $\mathrm{ZrO}_{2}$-on-steel tribo-couples

\begin{tabular}{lccc}
\hline Tribo-couple & $\begin{array}{c}\text { Soot concentration } \\
(\% \text { wt. } / \text { wt. })\end{array}$ & $\begin{array}{c}\text { Coefficient of friction } \\
(\mu)\end{array}$ & $\begin{array}{c}\text { Wear rate }\left(\times 10^{-9}\right. \\
\left.\mathrm{mm}^{3} / \mathrm{N}-\mathrm{m}\right)\end{array}$ \\
\hline Steel-on steel & 0 & $0.123 \pm 0.003$ & $3.62 \pm 0.08$ \\
& 2 & $0.153 \pm 0.033$ & $21.04 \pm 1.31$ \\
& 4 & $0.161 \pm 0.036$ & $36.69 \pm 0.77$ \\
$\mathrm{Si}_{3} \mathrm{~N}_{4}$-on-steel & 6 & $0.354 \pm 0.078$ & $56.88 \pm 1.17$ \\
& 0 & $0.084 \pm 0.005$ & $0.23 \pm 0.01$ \\
& 2 & $0.086 \pm 0.011$ & $0.74 \pm 0.07$ \\
& 4 & $0.088 \pm 0.013$ & $2.99 \pm 0.36$ \\
$\mathrm{ZrO}_{2}$-on-steel & 6 & $0.144 \pm 0.019$ & $4.85 \pm 0.70$ \\
& 0 & $0.033 \pm 0.003$ & $0.83 \pm 0.02$ \\
& 2 & $0.061 \pm 0.010$ & $0.85 \pm 0.07$ \\
& 4 & $0.087 \pm 0.005$ & $3.77 \pm 0.86$ \\
& 6 & $0.227 \pm 0.030$ & $5.43 \pm 1.17$ \\
\hline
\end{tabular}

\subsection{Effect of soot on viscosity}

Table 4 shows the viscosity of oil samples at different concentrations of soot contaminant. Viscosity increased in a linear manner as the concentration of soot increased in lubricant. Soot particles react with dispersant molecules and make long hydrocarbon chain (Smiechowski and Lvovich, 2005). Thus, it increases the average size of particles at micro level and causes oil thickening. Thus, viscosity of lubricant tends to increase (George et al., 2007), which affects wear adversely. Oil thickening causes pumping problems and reduces the lubricant availability. Ultimately, it affects the lubrication and becomes the reason of lubrication starvation and increases the wear problems.

Table 4 Viscosity of lubricant oil at different soot concentrations

\begin{tabular}{lc}
\hline Oil type & Viscosity $(c P)$ \\
\hline SAE20W40 + 0\% soot & 211 \\
SAE20W40 $+2 \%$ soot & 253 \\
SAE20W40 + 4\% soot & 299 \\
SAE20W40 +6\% soot & 342 \\
\hline
\end{tabular}

\subsection{Effect of soot on friction}

Figure 2 shows the comparison of average value of coefficient of friction over steady state for steel-on-steel $\mathrm{Si}_{3} \mathrm{~N}_{4}$-on-steel and $\mathrm{ZrO}_{2}$-on-steel sliding contacts. For steel-on-steel contact, it increased slightly upto $4 \%$ soot due to the pro-abrasive nature of soot particles (Mufti and Priest, 2003). The availability of dispersant additive in lubricant could disperse the soot particles at $2 \%$ and $4 \%$ soot concentration. However, at $6 \%$ soot concentration, dispersant was not capable enough to stop the formation of large clusters of soot particles that causes lubrication starvation at the contact. Soot particles remove 
the protective anti-wear layer and causes direct metal to metal contact. More dynamic response occurred at $6 \%$ soot level which shows the ineffectiveness of additives at higher concentration of soot contaminant to disperse the soot particles.

Figure 2 Comparison of steady state coefficient of friction at varying levels of soot concentration for steel-on-steel, $\mathrm{Si}_{3} \mathrm{~N}_{4}$-on-steel and $\mathrm{ZrO}_{2}$-on-steel (see online version for colours)

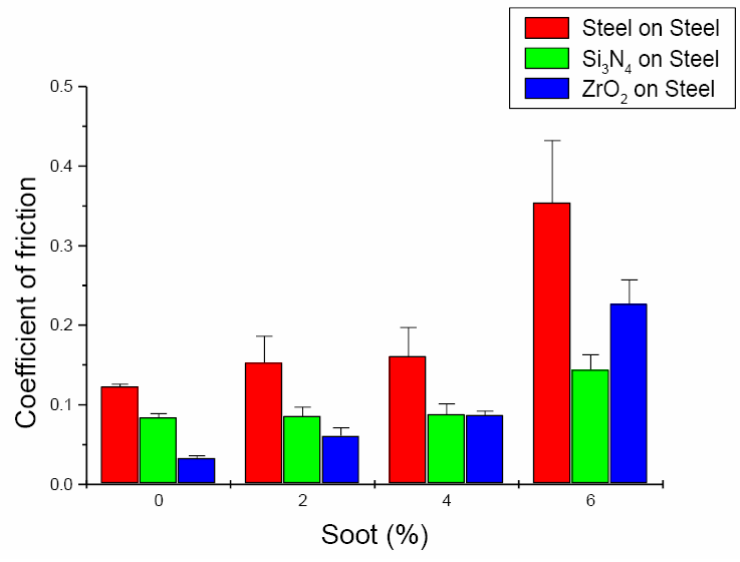

For $\mathrm{Si}_{3} \mathrm{~N}_{4}$-on-steel, similar trend was observed as steel-on-steel contact. There was no significant increment upto $4 \%$ soot concentration while significant effect was found at $6 \%$ soot concentration because of ineffectiveness of dispersant.

For $\mathrm{ZrO}_{2}$-on-steel contact, the rate of increment of coefficient of friction was higher compared to other two tribo-couples as shown in Figure 2. A clear difference in the coefficient of friction can be observed at each level of soot. Zirconia surface was more affected by soot particles compare to steel and silicon nitride. Soot particles caused rougher surface due to the micro-pits formed by delamination mechanism and resulted in increased friction and later the role of delamination mechanism on friction is discussed in post-test analysis.

\subsection{Effect of soot on wear}

Figure 3 shows the effect of soot on wear at different level of soot concentration for steel-on-steel, $\mathrm{Si}_{3} \mathrm{~N}_{4}$-on-steel and $\mathrm{ZrO}_{2}$-on-steel sliding contacts. Wear rate increases as the soot level increases due to the pro abrasive nature of soot particles (Mufti and Priest, 2003).

The $6 \%$ soot concentration level has the highest influence on wear parameter across the three tribo-couple materials. At this level, dispersant becomes less effective to separate the soot particles and allows them to agglomerate. Subsequently, agglomerated soot particles become large clusters and increase the probability of oil starvation in between the entrainment contact regions of pin and disc. Specifically, in steel-on-steel contact, this leads to metal to metal contact and tends to increase the wear. In SEM image analysis on pin worn surfaces, large grooves were observed at entrainment regions. This clearly indicates agglomeration of soot particles at higher concentration level (ChinasCastillo and Spikes, 2004). 
Figure 3 Comparison of SWR calculated from pin wear scar at different concentration of diesel soot for steel-on-steel, $\mathrm{Si}_{3} \mathrm{~N}_{4}$-on-steel and $\mathrm{ZrO}_{2}$-on-steel (see online version for colours)

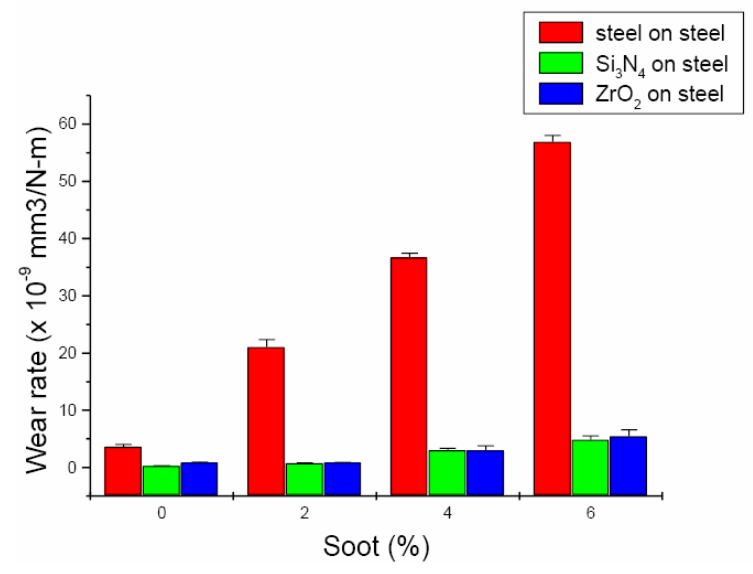

For silicon nitride-on-steel tribo-couple, wear rate was also found to be increasing with increment in soot concentration as for metallic contact as shown in Figure 3. Delamination wear mechanism was found on worn out surfaces of zirconia pins. The high contact pressure, friction induced temperature and continuous penetration of soot particles create stresses in the contacting surfaces. Due to the high stresses at pores, crack propagation occurs which leads to grain pull-out, resulting in wear debris (Kaneta et al., 2006). More micro-pits were observed as the soot concentration increased in lubricant, which is discussed in the post-test analysis. Figure 3 clearly shows the increasing wear rate as soot level increased.

In hybrid contacts, wear rate was found much less compared to metallic contact as shown in Figure 3. Due to the interatomic bonding and higher hardness of silicon nitride and zirconia, it is wear resistant and soot particles become less effective and cause less wear compare to steel sliding contacts (Green et al., 2006). As the soot level increases in the case of hybrid contacts, wear rate increases slightly with soot levels but marginally compared with steel-on-steel contact.

\section{Post-test analysis}

The wear mechanisms were identified using SEM analysis of worn pins. Figure 4(a1), Figure 4(b1), Figure 4(c1) and Figure 4(d1) show the circular shape wear scars and Figures 4(a2), (b2), (c2) and (d2) show the magnified images on the worn surfaces of steel pin samples for $0 \%$ soot, $2 \%$ soot, $4 \%$ soot and $6 \%$ soot level respectively. The arrow on the micrographs shows the direction of sliding. For uncontaminated oil, plastic deformation occurred with flattened ridges and smooth surface as shown in Figure 4(a2). Abrasive wear was identified as primary wear mechanism for all soot contaminated oil samples. Figure 4(b2) shows widely spaced grooves for $2 \%$ soot contaminated oil. At $4 \%$ soot concentration, Figure 4(c2), more abrasive grooving occurred and increased the percentage of wear debris. Further this process continues and causes more wear damage at $6 \%$ soot concentration as shown in Figure 4(d2). Except 2\% soot level, in the remaining soot levels plastically deformed and broken groove edges were observed. 
Figure 4 SEM micrographs of pin wear scars for different concentration of soot contamination: (a) $0 \%$ soot (b) $2 \%$ soot (c) $4 \%$ soot (d) $6 \%$ soot; for steel-on-steel contact

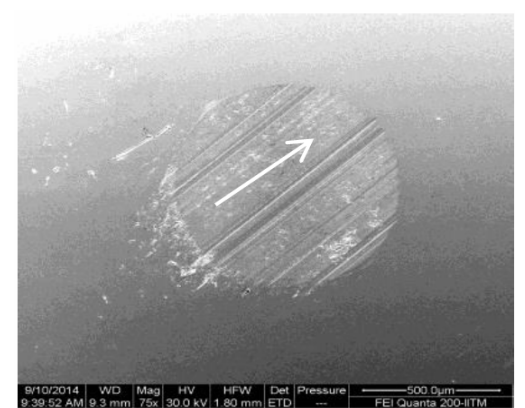

(a1)

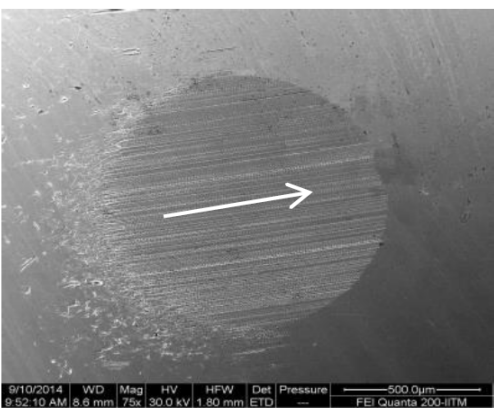

(b1)

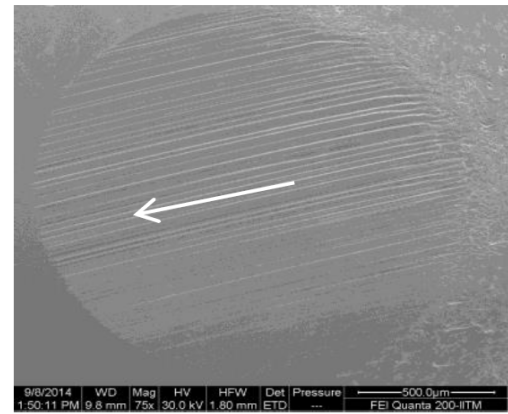

(c1)

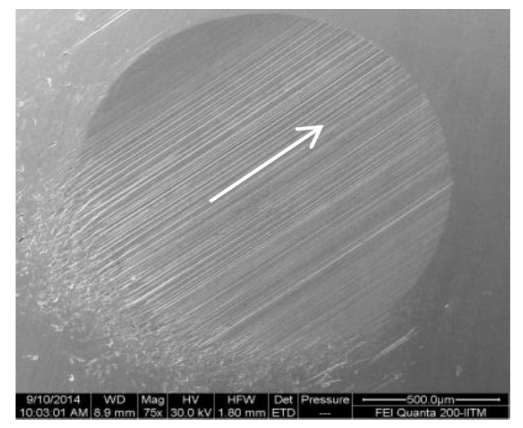

(d1)

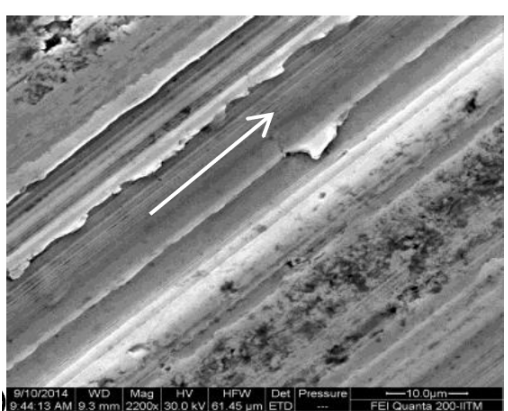

(a2)

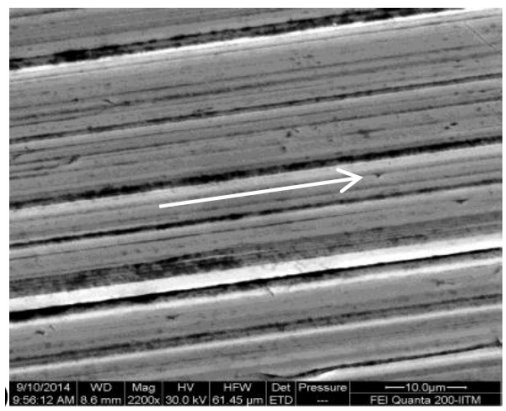

(b2)

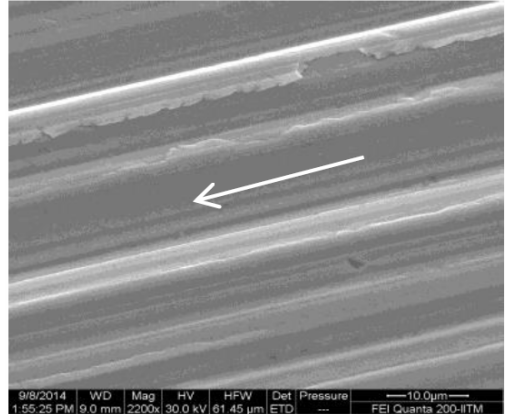

(c2)

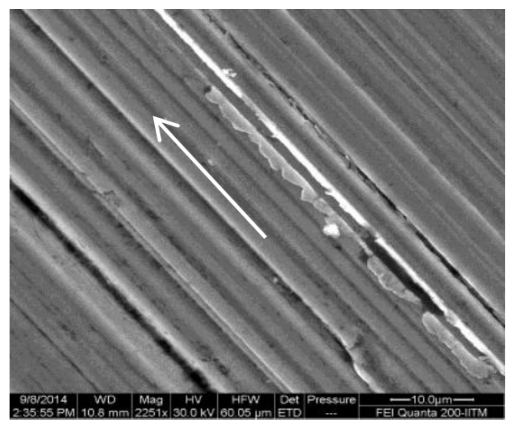

(d2) 
Figure 5 SEM micrographs of pin-wear scars for different concentration of soot contamination: (a) $0 \% \operatorname{soot}\left(\right.$ b) $2 \%$ soot (c) $4 \%$ soot (d) $6 \%$ soot; for $\mathrm{Si}_{3} \mathrm{~N}_{4}$-on-steel

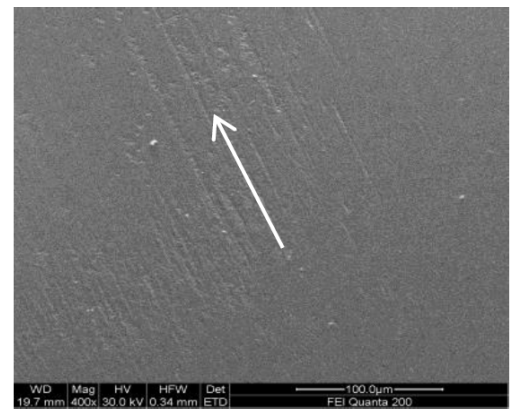

(a1)

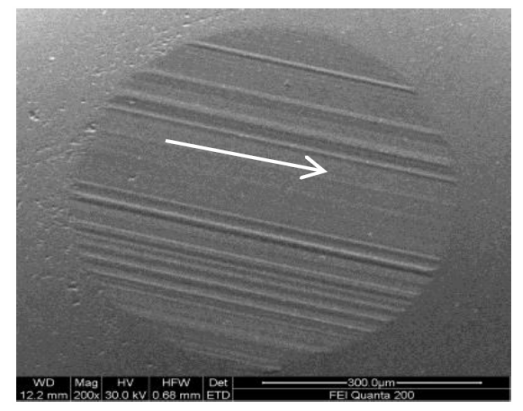

(b1)

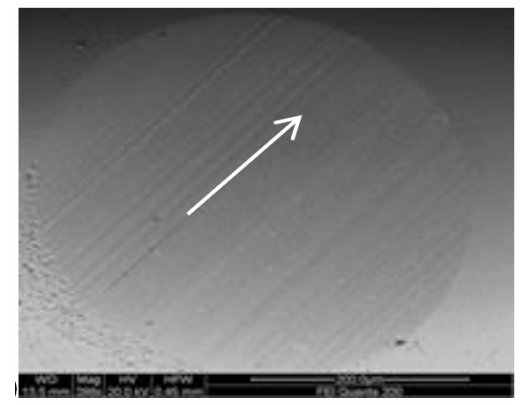

(c1)

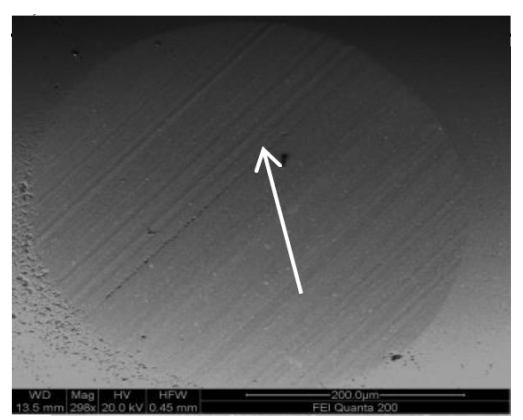

(d1)

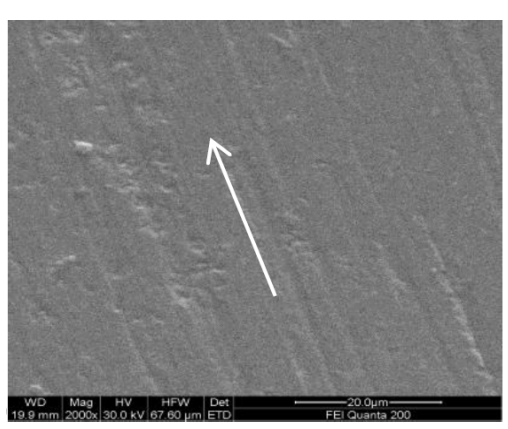

(a2)

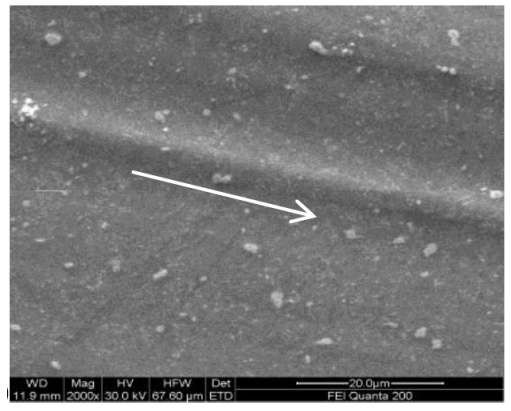

(b2)

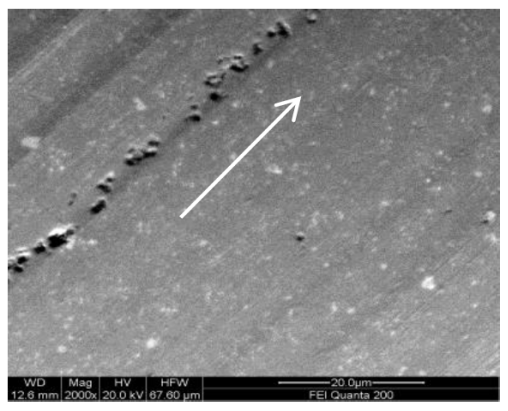

(c2)

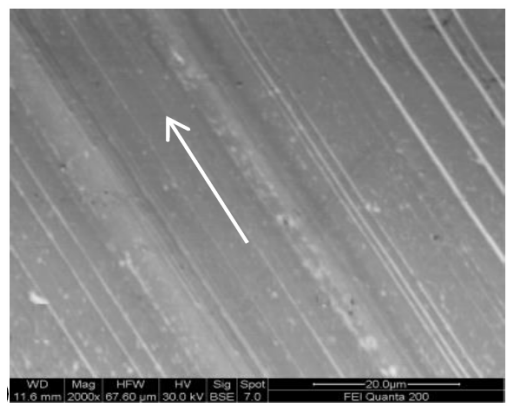

$(\mathrm{d} 2)$ 
Figure 5 shows the wear scars of silicon nitride pins to identify the wear mechanism at different soot levels. For contaminated oil, more circular scars were identified and evenly worn as shown in Figures 5(b1), 5(c1) and 5(d1). Higher soot concentration follows abrasive wear to more polished worn surfaces as shown in Figure 5(d2). At minimum oil film thickness regions, more grooves occurred due to the oil starvation in the case of soot agglomeration.

Figure 6 SEM micrographs of pin wear scars at $0 \%$ soot concentration for $\mathrm{ZrO}_{2}$-on-steel contact

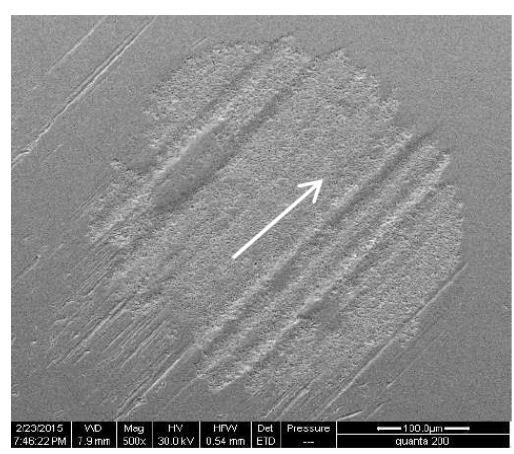

(a1)

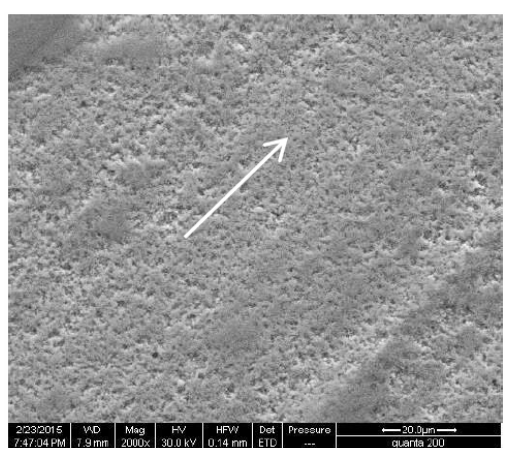

(a2)

Figure 7 SEM micrographs of pin wear scars at $2 \%$ soot concentration for $\mathrm{ZrO}_{2}$-on-steel contact (see online version for colours)

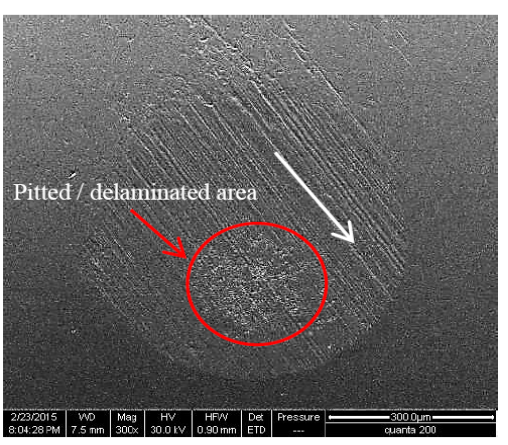

(a)

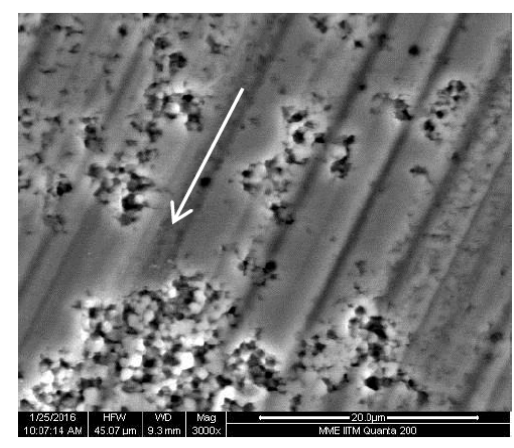

(c)

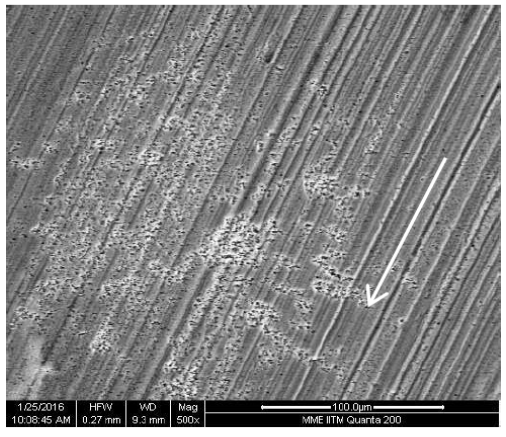

(b)

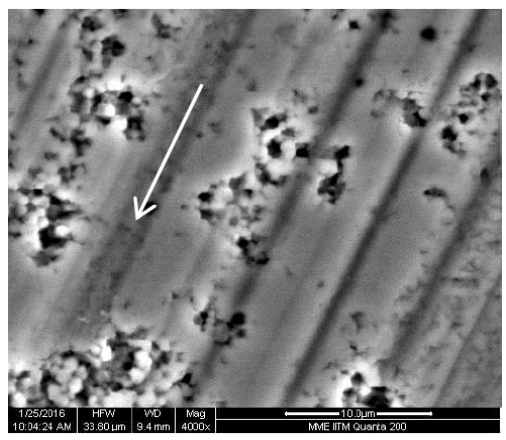

(d) 
More interesting results were found in SEM image analysis of zirconia worn pins. In uncontaminated oil, much smoothed worn surface area was observed as shown in Figure 6. In the presence of soot particles, abrasive grooves and pits were found on the worn surface and increased as the soot concentration increased. Figure 7 shows the removal of grain pull-out on the highly stressed local areas. These areas increased as the soot level increased as shown in Figure 8 and Figure 9. Table 5 shows the delaminated area of zirconia pins by different level of soot concentration. The area was calculated using SEM images of zirconia pins by mapping method. It can be clearly stated that the area affected (pits) is directly proportional to soot concentration.

Figure 8 SEM micrographs of pin wear scars at $4 \%$ soot concentration for $\mathrm{ZrO}_{2}$-on-steel contact (see online version for colours)

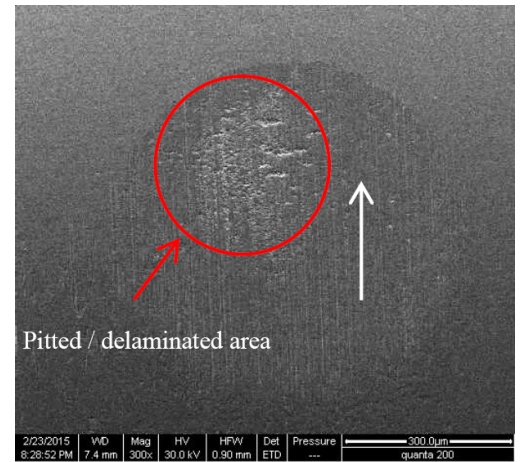

(a)

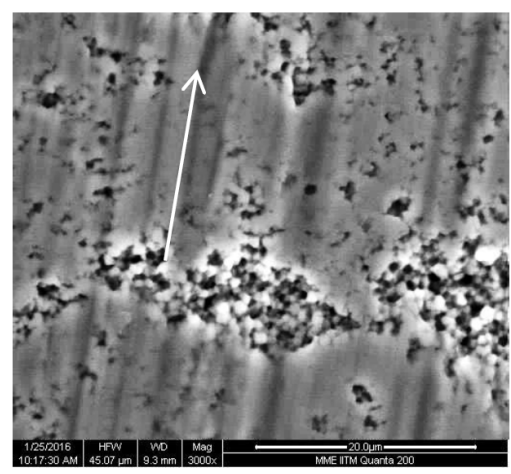

(c)

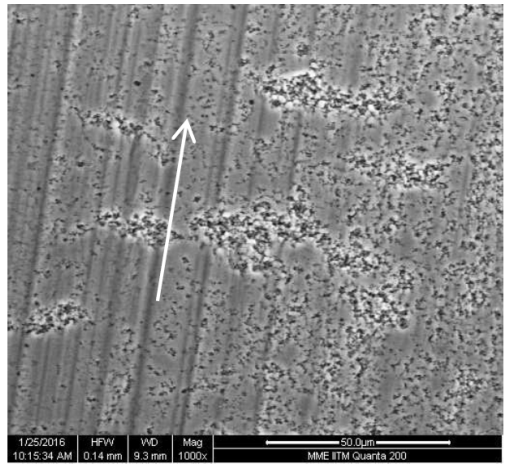

(b)

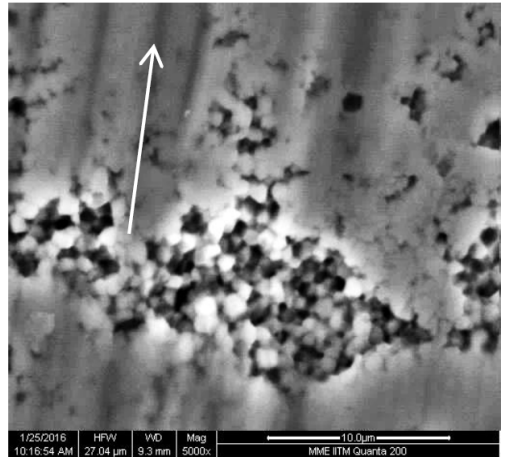

(d)

Table 5 Delaminated area of zirconia pins at various level of soot concentration

\begin{tabular}{lc}
\hline Soot (\% wt./wt.) & Delaminated area $\left(\times 10^{-9} \mathrm{~m}^{2}\right)$ \\
\hline 2 & 26.67 \\
4 & 53.34 \\
6 & 88.89 \\
\hline
\end{tabular}


Figure 9 SEM micrographs of pin wear scars at $6 \%$ soot concentration for $\mathrm{ZrO}_{2}$-on-steel contact (see online version for colours)

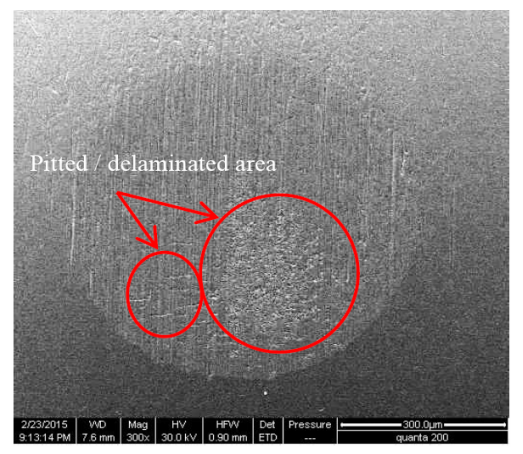

(a)

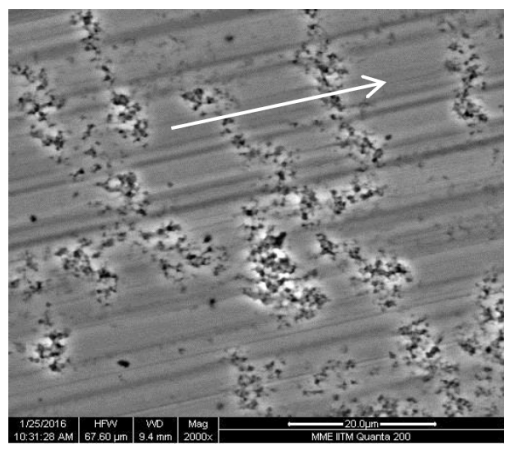

(c)

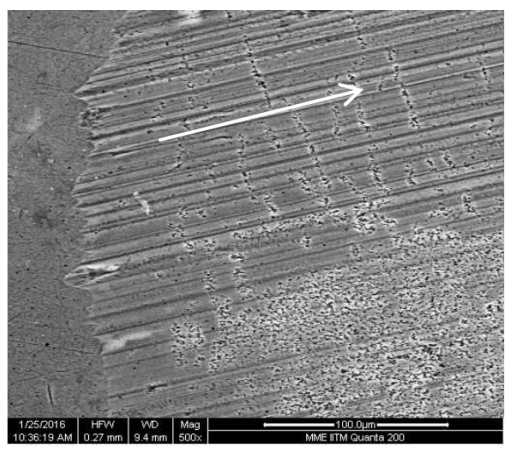

(b)

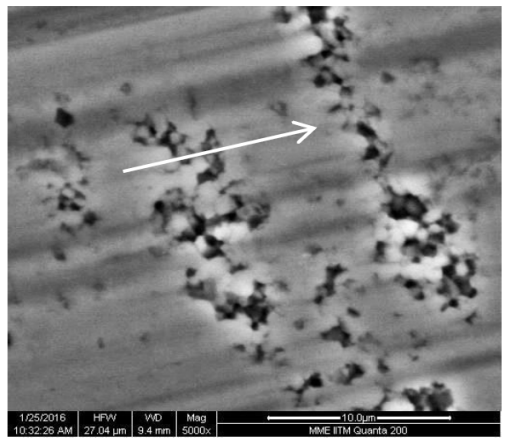

(d)

Figure 10 A schematic of wear mechanism in presence of soot particles for zirconia against steel (see online version for colours)

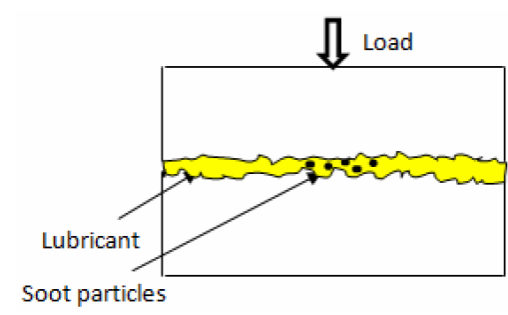

(a)

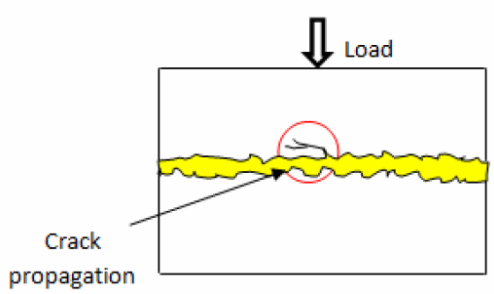

(c)

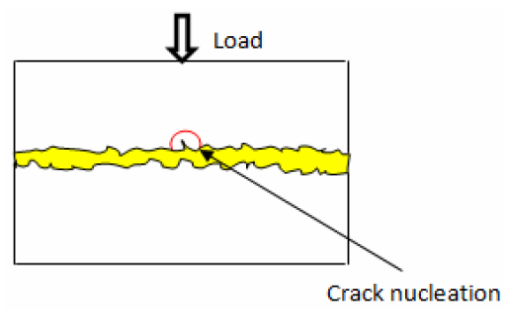

(b)

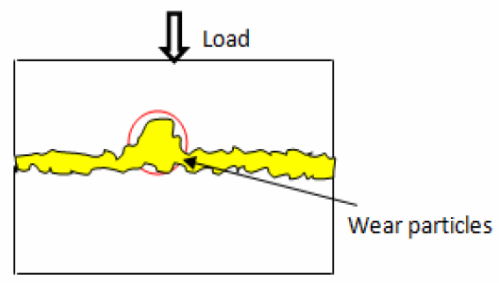

(d) 
A wear mechanism can be proposed for zirconia in presence of soot particles. Figure 10 shows the schematic diagram of delamination wear on the zirconia pin surface due to the soot particles. Particles making simultaneous contact with opposing surfaces focus the load onto a small area, which can result in the generation of sub-surface cracks. Internal stresses, developed due to high contact pressure and penetration of soot particles, promote micro-crack nucleation at pores and grain boundaries. When these subsurface cracks intersect at the contact surface of the body, the removal of particles starts. It is like the delamination theory of wear.

\section{Conclusions}

The major conclusions from the present experimental study are stated below:

- Soot affected all tribo-couples of steel, silicon nitride and zirconia against steel in terms of friction and wear.

- In the case of zirconia, the rate of increment of friction was found to be more compared to steel and silicon nitride.

- A delamination wear mechanism is proposed for zirconia in presence of soot particles.

- In the presence of soot, silicon nitride showed the lowest friction and wear of all tribo-couples.

\section{References}

Bhattarcharya, S., Sarkar, B. and Mukherjee, R.N. (2008) 'Multi-criteria decision making for the evaluation of the performance of bearing materials', Int. J. Materials and Structural Integrity, Vol. 1, No. 4, pp.371-377.

Chinas-Castillo, F. and Spikes, H.A. (2004), 'The behavior of diluted sooted oils in lubricated contacts', Tribology Letters, Vol. 16, No. 4, pp.317-322.

Gee, M.G. (1993) Guidelines for Unlubricated Sliding Wear Tests, Part 1 and 2, National Physical Laboratory.

George, S., Balla, S., Gautam, V. and Gautam, M. (2007) 'Effect of diesel soot on lubricant oil viscosity', Department of Mechanical and Aerospace Engineering, West Virginia University, Morgantown 26506, USA, Tribology International, Vol. 40, No. 5, pp.809-818.

Green, D.A., Lewis, R. and Dwyer-Joyce, R.S. (2006) 'Wear effects and mechanisms of soot-contaminated automotive lubricants', Proc. IMechE, Part J: J. Engineering Tribology, Vol. 220, No. 3, pp.159-169.

Hannink, R.H.J., Murray, M.J. and Scott, H.G. (1984) 'Friction and wear of partially stabilized zirconia: basic science and practical applications', Wear, Vol. 100, Nos. 1-3, pp.355-366.

Kaneta, M., Irie, T., Nishikawa, H. and Matsuda, K. (2006) 'Effects of soot on wear in elastohydrodynamic lubrication contacts', Proc. IMechE, Part J: J. Engineering Tribology, Vol. 220, No. 3, pp.307-317.

Lapuerta, M. and Ballesteros, R. (2009) 'The effect of diesel engine conditions on the size and morphology of soot particles', Int. J. Vehicle Design, Vol. 50, Nos. 1/2/3/4, pp.91-106.

Liao, N., Zhang, M., Raj, R. and Zhou, S. (2016) 'Predicting structural properties of amorphous silicon carbonnitride by atomistic simulation', IJMSI, Vol. 10, No. 1/2/3, pp.63-69. 
Mufti, R.A. and Priest, M. (2003) 'Experimental and theoretical study of instantaneous engine valve train friction', J. Tribology, Vol. 125, No. 8, pp.628-637.

Penchaliah, R., Harvey, T.J., Wood, R.J.K., Nelson, K. and Powrie, H.E.G. (2011) 'The effects of diesel contaminants on tribological performance on sliding steel on steel contacts', Proc. IMechE, Part J: J. Engineering Tribology, Vol. 225, No. 8, pp.779-797.

Silicon nitride material properties [online] http://www.vwimpex.com/ (accessed 13 January 2015).

Smiechowski, M.F. and Lvovich, V.F. (2005) 'Characterization of non-aqueous dispersions of carbon black nanoparticles by electrochemical impedance spectroscopy', Journal of Electroanalytical Chemistry, Vol. 577, No. 1, pp.67-78.

Soejimaa, M., Ejimaa, Y., Uemorib, K. and Kawasakib, M. (2002) 'Studies on friction and wear characteristics of cam and follower: influences of soot contamination in engine oil', JSAE Review, Vol. 23, No. 1, pp.113-119.

Wyczalek, F.A. (1990) Structural Ceramics in Automotive Engines - Integration of Design, Development and Manufacturing Procedures, SAE Technical Paper Series, 1SSN: 0148-7191.

Zirconia material properties [online] http://www.xzballbearing.com (accessed 14 January 2015). 